\title{
The patient enablement instrument for back pain: reliability, content validity, construct validity and responsiveness
}

\author{
A. Molgaard Nielsen ${ }^{1 *}\left(\mathbb{D}\right.$, J. Hartvigsen ${ }^{1,2}$, A. Kongsted ${ }^{1,2}$, B. Öberg ${ }^{3}$, P. Enthoven ${ }^{3}$, A. Abbott ${ }^{3}$ and \\ H. H. Lauridsen ${ }^{1}$
}

\begin{abstract}
Background: Currently, there are no outcome measures assessing the ability of people with non-specific low back pain to self-manage their illness. Inspired by the 'Patient Enablement Instrument', we developed the Patient Enablement Instrument for Back Pain (PEI-BP). The aim of this study was to describe the development of the Patient Enablement Instrument for Back Pain (PEI-BP) and investigate content validity, construct validity, internal consistency, testretest reliability, measurement error, responsiveness and floor and ceiling effects.

Methods: The PEI-BP consists of 6 items that are rated on a 0-10 Numeric Rating Scale. Measurement properties were evaluated using the COSMIN taxonomy and were based on three cohorts from primary care with low back pain: The content validity cohort $(N=14)$ which participated in semi-structured interviews, the $G L A: D^{\circledR}$ Back cohort $(N=272)$ and the test-retest cohort $(N=37)$ which both completed self-reported questionnaires. For construct validity and responsiveness, enablement was compared to disability (Oswestry Disability Index), back pain beliefs (Brief Illness Perception Questionnaire), fear avoidance (Fear-Avoidance Beliefs Questionnaire-physical activity), mental health (SF-36), educational level and number of previous episodes of low back pain.
\end{abstract}

Results: The PEI-BP was found to have acceptable content validity, construct validity, reliability (internal consistency, test-retest reliability and measurement error) and responsiveness. The Smallest Detectable Change was 10.1 points illustrating that a patient would have to change more than $1 / 6$ of the scale range for it to be a true change. A skewed distribution towards the high scores were found at baseline indicating a potentially problematic ceiling effect in the current population.

Conclusions: The PEI-BP can be considered a valid and reliable tool to measure enablement on people seeking care for non-specific LBP. Further testing of the PEI-BP in populations with more severe LBP is recommended.

Trial registration: Not applicable.

Keywords: Validity, Reliability, Primary care, Low back pain, Outcome assessment

*Correspondence: amnielsen@health.sdu.dk

${ }^{1}$ Department of Sports Science and Clinical Biomechanics, University of Southern Denmark, Campusvej 55, 5230 Odense M, Denmark

Full list of author information is available at the end of the article

\section{Background}

Most people experience low back pain (LBP) some time in their life [1], and most LBP is classified as non-specific because the exact nociceptive source cannot be identified with certainty [2]. Most recent guidelines for the management of non-specific LBP endorse interventions that support self-management [3]. However, currently there are original author(s) and the source, provide a link to the Creative Commons licence, and indicate if changes were made. The images or other third party material in this article are included in the article's Creative Commons licence, unless indicated otherwise in a credit line to the material. If material is not included in the article's Creative Commons licence and your intended use is not permitted by statutory regulation or exceeds the permitted use, you will need to obtain permission directly from the copyright holder. To view a copy of this licence, visit http://creativecommons.org/licenses/by/4.0/. The Creative Commons Public Domain Dedication waiver (http://creativeco mmons.org/publicdomain/zero/1.0/) applies to the data made available in this article, unless otherwise stated in a credit line to the data. 
no reliable ways of measuring the concept of the patients' ability to manage their illness specific to non-specific LBP, as the most commonly used outcome measures are pain, disability and quality of life [4].

In 1997 Howie et al. presented the concept of enablement representing patients' empowerment and ability to understand and cope with their health and illness. In order to measure enablement, they developed the 'Patient Enablement Instrument' (PEI) based on the theory that other important outcomes will improve if the patients experience increased enablement after a consultation in primary care [5-8]. The PEI has since been translated to multiple languages and has generally shown moderate to good validity and reliability in different settings [7, 9-17]. However, there are limitations with the use of the PEI as an outcome measure [13] including that the PEI provides a retrospective transition rating at one time-point after an intervention challenging the measurement of change over time (responsiveness) [18].

Inspired by the PEI, researchers from Denmark and Sweden created the Patient Enablement Instrument for Back Pain (PEI-BP) which could potentially be used as an outcome measure for interventions aiming to improve self-management in people who seek care for LBP. However, before using the instrument as an outcome measure in research settings or in clinical practice, further investigation of the clinimetric properties of the instrument are needed.

Therefore, the aim of this project was to investigate the validity, reliability and responsiveness of the Patient Enablement Instrument for Back Pain. The specific objectives were to describe the development of the PEI-BP and investigate content validity, construct validity, internal consistency, test-retest reliability, measurement error, responsiveness and floor and ceiling effects when applied to patients with non-specific LBP who consult either chiropractors or physiotherapists in Denmark.

\section{Methods \\ Development of the patient enablement instrument for back pain (PEI-BP)}

The PEI-BP was adapted from the original PEI $[5,7,8]$ with the aim of being able to measure patients' perceived change in ability to understand and cope with their back problem. We convened a group of experienced back pain researchers from Denmark and Sweden (JH, AK, BÖ, $\mathrm{PE}, \mathrm{AA})$ and discussed needed modifications and arrived at the following changes from the original PEI: (1) The questions in PEI-BP focus on back pain and not illness in general, (2) it enquires about the patient's state during the past week which allow for measuring time specific changes by repeating measures of PEI-BP before and after an intervention and, (3) the responses to the 6 questions are rated on $0-10$ point Numeric Rating Scales as opposed to 0-2 point scales with the aim of increasing sensitivity to change over time, i.e. responsiveness.

The PEI-BP consists of 6 items measured on a $0-10$ numeric rating scale $(0=$ to a very low degree; $10=$ to a very high degree) with a total maximum score of 60 , with high scores indicating higher enablement. To make the PEI-BP available to international researchers, an English translation and cross-cultural adaptation of the PEI-BP was conducted by two independent native-English speaking persons with non-clinical backgrounds. The final translation committee also included two health professionals with one of these being an expert in the methodology. There were minor differences when comparing the translations of the PEI-BP from Danish to English, however, the translation committee reached consensus after discussions on the content of the questions. The Danish PEI-BP was used in this project and is available in Additional file 1 which also includes an English and Swedish translation. All versions of the PEI-BP are available from www.spoergeskemaer.dk/pei-bp.

\section{Testing of the PEI-BP}

Measurement properties for the PEI-BP were evaluated based on three cohorts: The content validity cohort, the GLA:D ${ }^{\circledR}$ Back cohort and the test-retest cohort. Reporting will follow Guidelines for Reporting Reliability and Agreement Studies (GRASS) by Kottner et al. [19] and will adhere to the standardised terminology and definitions of measurement properties as described in the COSMIN (COnsensus-based Standards for the selection of health Measurement INstruments) taxonomy [18].

\section{The content validity cohort}

From March and until May 2017, selected physiotherapy and chiropractic clinics with group-based back training were contacted by two student assistants from the University of Southern Denmark. Volunteering clinics were asked to identify five patients with back pain who were willing to participate in a semi-structured interview. The patients should participate in supervised training (individually or group-based), be at least 18 years of age and have had back pain for at least 4 weeks before the first appointment in the clinic. Consenting participants received the PEI-BP questionnaire at the clinic and were asked to complete it the same day. The clinics sent contact details from the consenting participants to the student assistants who also completed the interviews.

\section{The GLA:D ${ }^{\circledR}$ back cohort}

The GLA:D ${ }^{\circledR}$ Back cohort was established to test the feasibility of implementing the GLA: $\mathrm{D}^{\circledR}$ Back programme 
in primary care chiropractic and physiotherapy clinics in Denmark [20]. Four chiropractic clinics and five physiotherapy clinics which had expressed interest in GLA:D ${ }^{\circledR}$ Back participated in the feasibility testing. Recruitment of patients was carried out between August and December 2017. Eligible patients had non-specific low back pain (LBP), were at least 18 years of age, and could speak and write Danish. There were no other firm criteria for inclusion or exclusion as clinicians decided in collaboration with the patients whether the GLA: $\mathrm{D}^{\circledR}$ Back intervention would be suitable for them. This study only included participants in the GLA:D ${ }^{\circledR}$ Back intervention arm of the feasibility study. Further details about the GLA: $\mathrm{D}^{\circledR}$ Back programme and the recruitment of clinics and patients have been reported previously [20-22].

A target sample size of at least 200 participants was planned for this cohort which was estimated to ensure a stable variance-covariance matrix in an exploratory factor analysis. A sample size of 4-10 participants per item and more than 100 subjects has been suggested as sufficient [23].

\section{The test-retest cohort}

The test-retest cohort was established specifically for this study by two student assistants at the University of Southern Denmark as data for analysing test-retest was not available from the GLA: ${ }^{\circledR}$ Back Cohort. Participants were recruited from two primary care physiotherapy and three chiropractic clinics in the region of Southern Denmark between September and November 2018. Inclusion criteria were established to recruit a comparable cohort based on the characteristics of the GLA:D ${ }^{\circledR}$ Back cohort: (1) at least 18 years of age, (2) LBP had impacted activities of daily living for more than 1 month, (3) at least 3 consultations for treatment within the past 2 years, (4) no pain below the knee and (5) could speak and understand Danish.

As the overall leg pain intensity of the GLA: $\mathrm{D}^{\circledR}$ Back Cohort was low, we deemed that including patients with 'no pain below the knee' was the best way of getting a comparable cohort.

For a valid test of reliability, at least 50 participants were expected to complete both questionnaires and with no change in back pain intensity between the two time points [24]. The study was advertised in the clinics and the secretaries were asked to help recruiting patients fulfilling the inclusion criteria. Interested patients signed an electronic consent form.

\section{Data collection}

In the content validity cohort semi-structured telephone interviews were conducted and audio recorded. The interviews included two main topics: (1) comprehensibility of each item of the questionnaire, and (2) the overall relevance of the questionnaire and response options. For each item, the respondents were asked about their interpretation of the item. Responses were compared to pre-defined response themes including "I don't know" and responses unrelated to these options were noted. The themes covered the types of responses that had been considered most likely for each item beforehand. The participants were also encouraged to add any comments they found relevant during the interview. Recruitment continued until the same responses were obtained, and during four subsequent interviews no new themes emerged.

In the GLA:D ${ }^{\circledR}$ Back and the test-retest cohorts, participants completed self-reported questionnaires which covered demographics, patient back pain history and core outcome domains for the evaluation of back pain in clinical trials according to the consensus statement by Chiarotto et al. [4]. Additionally, more specific instruments measuring aspects related to the patients' abilities of selfmanagement were included. Details about the PEI-BP are described above, and further details of the remaining content of the self-reported questionnaires are reported in Table 1.

In the GLA:D $D^{\circledR}$ Back cohort, the questionnaire was sent electronically using the REDCap software provided and supported by the Open Patient data Explorative Network (OPEN) [37]. Participants received an e-mail with a link to the questionnaires on the day of the baseline consultation and 4 months later. If no response within 3 days, a reminder was sent.

In the test-retest cohort, the questionnaires were sent electronically using the survey-tool SurveyXact provided and supported by Ramboll [38]. Consenting participants received an e-mail asking them to complete the online baseline and follow-up questionnaires with 3-5 days in between. If no response within 2 days, a reminder was sent. If still no response within another couple of days, the participant was reminded using a phone call.

\section{Statistical analysis}

In the descriptive analysis, nominal scale variables were presented as proportions and continuous scale variables as mean and standard deviation. Baseline comparisons within the GLA: $\mathrm{D}^{\circledR}$ Back cohort between the participants who completed the baseline and follow-up questionnaires and the ones who only completed the baseline questionnaire were tested using $X^{2}$ test for nominal variables and Mann-Whitney $U$ test for continuous variables. Using the same test strategy, baseline comparisons were performed between the GLA:D ${ }^{\circledR}$ Back cohort and the test-retest cohort. A p-value $<0.05$ was considered 
Table 1 Description of the baseline characteristics and outcome variables collected in the three cohorts of participants

\begin{tabular}{|c|c|c|c|}
\hline & $\begin{array}{l}\text { Content } \\
\text { validity } \\
\text { cohort }\end{array}$ & $\begin{array}{l}\text { GLA:D } \\
\text { Back } \\
\text { cohort }\end{array}$ & $\begin{array}{l}\text { Test- } \\
\text { retest } \\
\text { cohort }\end{array}$ \\
\hline \multicolumn{4}{|l|}{ Baseline characteristics } \\
\hline Age, years & $\checkmark$ & $\checkmark$ & $\checkmark$ \\
\hline Sex, male/female & $\checkmark$ & $\checkmark$ & $\checkmark$ \\
\hline $\begin{array}{l}\text { Education: no qualification; public school; high school; vocational training; higher education }<3 \text { years; higher edu- } \\
\text { cation 3-4 years; higher education }>4 \text { years }\end{array}$ & $\checkmark$ & $\checkmark$ & $\checkmark$ \\
\hline Back pain intensity: Numeric rating scale $0-10(0=$ no pain, $10=$ worst imaginable pain) $[25]$ & $\checkmark$ & $\checkmark$ & $\checkmark$ \\
\hline Leg pain intensity: Numeric rating scale $0-10(0=$ no pain, $10=$ worst imaginable pain) [25] & $\checkmark$ & $\checkmark$ & $\checkmark$ \\
\hline Episode duration (5 -point scale): 0-2 weeks, 2-4 weeks, 4-12 weeks, 3-12 months, > 1 year & $\checkmark$ & $\checkmark$ & $\checkmark$ \\
\hline Previous back pain episodes (4-point scale): 0 episodes, 1 episode, 2-3 episodes, > 3 episodes & $\checkmark$ & $\checkmark$ & $\checkmark$ \\
\hline $\begin{array}{l}\text { STarT Back Tool (SBT): Contains } 9 \text { items each with a score of } 0 \text { or } 1 \text { with a higher score indicating higher risk of poor } \\
\text { prognosis. Risk groups are based on the total score and a sub score (Q5-9): Low risk ( } 3 \text { or less on the total score), } \\
\text { medium risk ( } 4 \text { or more on total score and } 3 \text { or less on sub score) and high risk ( } 4 \text { or more on both total score and } \\
\text { sub score) }[26,27]\end{array}$ & & $\checkmark$ & $\checkmark$ \\
\hline \multicolumn{4}{|l|}{ Outcome measures } \\
\hline \multicolumn{4}{|l|}{ Pain-related disability } \\
\hline $\begin{array}{l}\text { Oswestry Disability Index (ODI): Contains } 10 \text { items (pain intensity, personal care, lifting, walking, sitting, standing, } \\
\text { sleeping, sex life, social life, traveling) each with } 6 \text { response options on a } 0-5 \text { point scale. The answers on the } 10 \\
\text { items are converted into a single score (0-100), higher scores indicate more disability [28-30] }\end{array}$ & & $\checkmark$ & $\checkmark$ \\
\hline \multicolumn{4}{|l|}{ Mental health } \\
\hline $\begin{array}{l}\text { Brief IIIness Perception Questionnaire (BIPQ): Contains } 9 \text { items each assessing one dimension of illness perception } \\
\text { (consequences, timeline, personal control, treatment control, identity, illness concern, coherence, emotional } \\
\text { representation and a causal item). Item } 1-8 \text { are scored on a } 11 \text {-point scale }(0-10) \text { and converted to a sum score } \\
\text { (range } 0-80 \text { ), higher scores reflects more threatening view of the back pain [31, 32] } \\
\text { For analysis of single items ( } 3 \text { and } 7 \text { ) the response categories were reversed, and a lower score reflected a more } \\
\text { threatening view of the back pain }\end{array}$ & & $\checkmark$ & \\
\hline $\begin{array}{l}\text { Fear-Avoidance Beliefs Questionnaire (FABQ) - physical activity subscale: Contains } 5 \text { items with Likert response } \\
\text { options scored on a } 0-6 \text { point scale }(0=\text { Completely disagree, } 6=\text { completely agree) of which item } 2-5 \text { are } \\
\text { included in the score (range } 0-24) \text {. Higher scores indicate higher fear avoidance beliefs }[33,34]\end{array}$ & & $\checkmark$ & \\
\hline $\begin{array}{l}\text { SF-36 subscale 'mental health': Contains } 5 \text { items on a } 1-6 \text { point scale }(1=\text { All of the time, } 6=\text { None of the time), } \\
\text { which are converted into a single score }(0-100) \text {. Higher scores indicate a more favorable mental health }[35,36]\end{array}$ & & $\checkmark$ & \\
\hline \multicolumn{4}{|l|}{ Quality of life } \\
\hline $\begin{array}{l}\text { SF-36 subscale 'social functioning limited by physical health': Contains } 1 \text { item on a } 1-6 \text { point scale }(1=\text { All of the } \\
\text { time, } 0=\text { None of the time). Higher scores indicate a more favorable social functioning }[35,36]\end{array}$ & & $\checkmark$ & \\
\hline
\end{tabular}

SF-36= Short Form 36, version 1.0

significant. If any of the 6 included items in the total score of PEI-BP was missing at baseline or follow-up, no sum-score was calculated, and the scale was discarded. Measurement properties of the PEI-BP were evaluated using the COSMIN taxonomy [24].

\section{Item analyses}

The 6 items of the PEI-BP were examined through item distribution, kurtosis and skewness. If less than $3 \%$ were missing for each item, this was considered acceptable [24].

\section{Content validity}

The interviews were analysed quantitatively by assessing, for each item, how many respondents had a similar interpretation of the question, that is if they chose the same pre-defined response theme. Further, it was summarised how many respondents considered the overall questionnaire easy to complete and relevant. Further comments from the participants during the interview were additionally taking into consideration when evaluating the overall content validity of the questionnaire.

\section{Construct validity}

Structural validity An explorative factor analysis (EFA) was conducted to identify the underlying factor structure of the PEI-BP. Initially, sampling adequacy was tested using Bartlett's Test of Sphericity and the Kaiser-MeyerOlkin test [39]. The EFA was carried out using a principal axis factor analysis with a polychoric correlation matrix combined with an oblique oblimin rotation and Kaiser normalisation to obtain meaningful and correlated fac- 
tors if present [40]. The number of factors was examined using a scree plot, and factors with eigenvalues of $>1$ were retained [24]. Factor loadings of $>0.7$ and communalities of $>0.5$ were considered satisfactory [39].

Hypothesis-testing This was assessed by formulating eight hypotheses regarding the size and direction of correlations. The hypotheses were between the PEI-BP summary score and selected baseline questions (Table 5), four instruments (BIPQ, ODI, FABQ, SF-36) and one individual item (BIPQ-3:"how much control do you feel you have over your back pain"). One additional hypothesis was formulated regarding the size and direction of the correlation between the second PEI-BP item ("to which degree were you able to understand your back problem") and the seventh BIPQ item ("how well do you feel you understand your back pain"). The relationships between the PEI-BP and other measurements were investigated using Spearman's rank correlation. The strength of the correlations was formulated according to Cohen's criteria (low $\leq 0.1$, moderate $>0.1 ; \leq 0.3$ and high $>0.5$ ) [41]. As an indicator of the strength of evidence for construct validity of the PEI-BP, the percentage of correctly predicted hypotheses were determined $[24,42]$.

\section{Reliability}

Internal consistency was determined from baseline data in the GLA:D ${ }^{\circledR}$ Back cohort study using Cronbach's $\alpha$. Alpha was established after completion of the factor analysis and was considered satisfactory between 0.7 and 0.9 [24].

Data from the test-retest cohort was used to assess the test-retest reliability using an Intra Class Correlation with $95 \%$ confident intervals (CI) based on a two-way mixed-effects model with single rater/measurement and absolute agreement (equivalent to an $\operatorname{ICC}(2.1) \mathrm{A}$ ). A value $\geq 0.70$ was considered acceptable $[24,43]$.

Measurement error was assessed using Bland and Altman plots [44]. The smallest detectable change (SDC) was defined as change outside the limits of agreement [45].

\section{Responsiveness}

Responsiveness was investigated using data from the GLA:D ${ }^{\circledR}$ Back cohort. Construct responsiveness was assessed by formulating six hypotheses regarding the size and direction of correlations between the PEI-BP change score and change scores of selected instruments (BIPQ, ODI, FABQ, SF-36) and the third BIPQ item [24, 46]. One additional hypothesis was formulated regarding the size and direction of the correlation between the change score of the second PEI-BP item and the seventh BIPQ item (Table 5).

\section{Floor and ceiling effects}

Floor and ceiling effects were assessed using both the classical method [47] and the"scale width" method [48]. The latter is defined as the capacity of a scale to have baseline scores far enough onto the scale (the smallest detectable change) to allow detection of change in scores over time [48]. Scale width was considered acceptable if no more than $15 \%$ of the subjects had baseline PEI sum scores falling outside the scale width either at the upper or lower end of the scale.

Statistical analyses were conducted using STATA/IC 16.1 (StataCorp LP, College Station, TX, USA).

\section{Results \\ Participant characteristics \\ The GLA:D ${ }^{\circledR}$ Back cohort}

For the GLA:D ${ }^{\circledR}$ Back cohort, a total of $272(79 \%)$ and 198 (58\%) participants responded to the baseline and followup questionnaires, respectively (Fig. 1). Comparison of baseline characteristics revealed no significant statistical differences between the participants who completed both questionnaires and the participants who only completed the baseline questionnaire when tested for age, sex, back pain intensity, episode duration, PEI-BP sum score and ODI sum score. The mean PEI-BP sum score increased from 41.8 (SD 10.8) at baseline to 48.2 (SD 10.0) at follow-up. Further baseline characteristics are available in Table 2.

\section{The test-retest cohort}

For the test-retest reliability study, 37 participants with non-specific LBP were included, who had complete responses on the PEI-BP and no significant change in pain between test and retest (Fig. 2). The response rate at

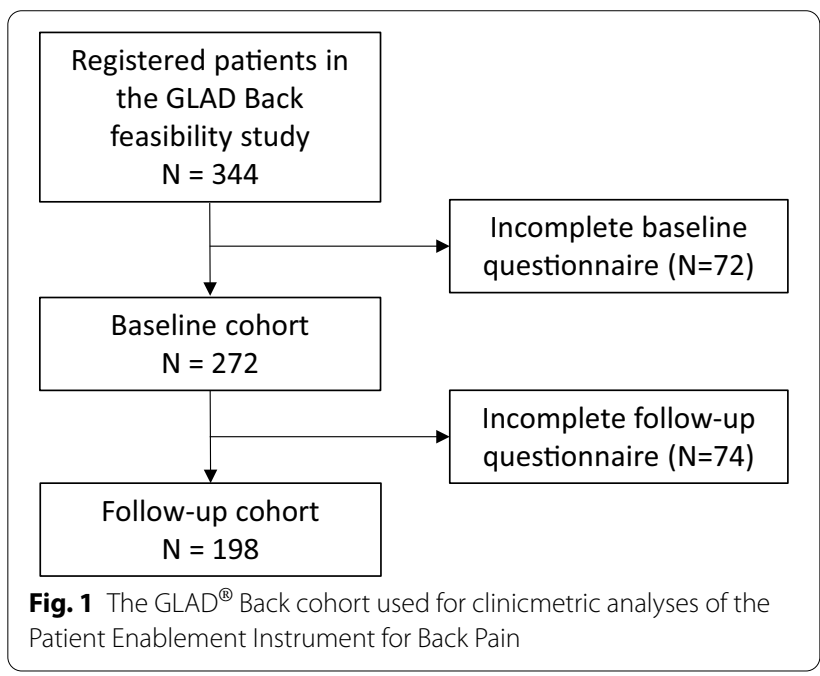


Table 2 Patient reported baseline characteristics for the cohorts of participants with non-specific low back pain

\begin{tabular}{|c|c|c|c|}
\hline & $\begin{array}{l}\text { Content validity } \\
\text { cohort } \\
N=14\end{array}$ & $\begin{array}{l}\text { GLA:D } D^{\circledR} \text { Back baseline } \\
\text { cohort } N=272\end{array}$ & $\begin{array}{l}\text { Test-retest cohort } \\
N=37\end{array}$ \\
\hline Age, mean (SD, years) & $56(8)$ & $53(12)$ & $52(13)$ \\
\hline Males, N (\%) & $3(21)$ & $57(21)$ & $13(35)$ \\
\hline \multicolumn{4}{|l|}{ Highest achieved education, N (\%) } \\
\hline No qualification & 0 & $1(0.4)$ & $2(5)$ \\
\hline Public school & 0 & $14(5)$ & $0(0)$ \\
\hline High school & 0 & $9(3)$ & $0(0)$ \\
\hline Vocational training & 10 & $75(28)$ & $7(19)$ \\
\hline Higher education $<3$ years & 1 & $37(14)$ & $3(8)$ \\
\hline Higher education 3-4 years & 2 & $100(37)$ & $18(49)$ \\
\hline Higher education $>4$ years & 1 & $26(10)$ & $6(16)$ \\
\hline Missing & 0 & $10(4)$ & $1(3)$ \\
\hline Back pain intensity (0-10 Numeric Rating Scale), mean (SD) & $4.1(2.1)$ & $5.0(2.3)$ & $5.9(2.4)$ \\
\hline Missing (\%) & 0 & $1(0.4)$ & 0 \\
\hline Leg pain intensity (0-10 Numeric Rating Scale), mean (SD) & $7(5.0)^{*}$ & $2.8(2.7)$ & $3.1(2.7)$ \\
\hline Missing (\%) & $0(0)$ & $0(0)$ & $0(0)$ \\
\hline \multicolumn{4}{|l|}{ Episode duration, N (\%) } \\
\hline $0-2$ weeks & 0 & $18(7)$ & $<1$ week = 5 (14) \\
\hline 2-4 weeks & 0 & $11(4)$ & $1-4$ weeks $=4(11)$ \\
\hline $4-12$ weeks & 2 & $18(7)$ & $5(14)$ \\
\hline $3-12$ months & 1 & $52(19)$ & $6(16)$ \\
\hline$>1$ year & 11 & $172(63)$ & $17(46)$ \\
\hline Missing & 0 & $1(0.4)$ & $0(0)$ \\
\hline \multicolumn{4}{|l|}{ Number of previous episodes, $\mathrm{N}(\%)$} \\
\hline 0 episodes & 1 & $67(25)$ & $3(8)$ \\
\hline 1 episode & 1 & $48(18)$ & $3(8)$ \\
\hline 2-3 episodes & 0 & $53(19)$ & $6(16)$ \\
\hline$>3$ episodes & 12 & $103(38)$ & $25(68)$ \\
\hline Missing & 0 & $1(0.4)$ & $0(0)$ \\
\hline Patient Enablement Instrument for back pain (0-60), mean (SD) & & $41.8(10.8)$ & $39.6(13.3)$ \\
\hline Missing, N (\%) [any of 6 items missing] & & $11(4)$ & $0(0)$ \\
\hline \multicolumn{4}{|l|}{ STarT Back Tool score, N (\%) } \\
\hline Low risk [any of 9 items missing] & & $156(57)$ & $19(51)$ \\
\hline Medium risk & & $68(25)$ & $8(22)$ \\
\hline High risk & & $48(18)$ & $8(22)$ \\
\hline Missing (items) & & $7(3)$ & $2(5)$ \\
\hline Oswestry Disability Index (0-100), mean (SD) & & $22.5(11.6)$ & $22.4(15.6)$ \\
\hline Missing, $N(\%)[\geq 4$ of 10 items missing] & & $0(0)$ & $0(0)$ \\
\hline Brief Illness Perception Questionnaire (0-80), mean (SD) & & $40.7(11.0)$ & \\
\hline Missing, $N(\%)[\geq 3$ of 8 items missing] & & $2(1)$ & \\
\hline Fear Avoidance Belief Questionnaire_-physical activity (0-24), mean (SD) & & $8.3(5.4)$ & \\
\hline Missing N (\%) (any of 4 items missing) & & $7(3)$ & \\
\hline \multicolumn{4}{|l|}{ SF-36 subscales } \\
\hline Mental health (0-100), mean (SD) & & $72.4(16.9)$ & \\
\hline Missing, N (\%) [any of 5 items missing] & & $6(2)$ & \\
\hline $\begin{array}{l}\text { Social functioning limited by physical } \\
\text { health }\end{array}$ & & $1.8(0.9)$ & \\
\hline Missing, $\mathrm{N}(\%)$ & & $0(0)$ & \\
\hline
\end{tabular}

SF-36 = Short Form 36

* Leg pain yes/no, N (\%) 


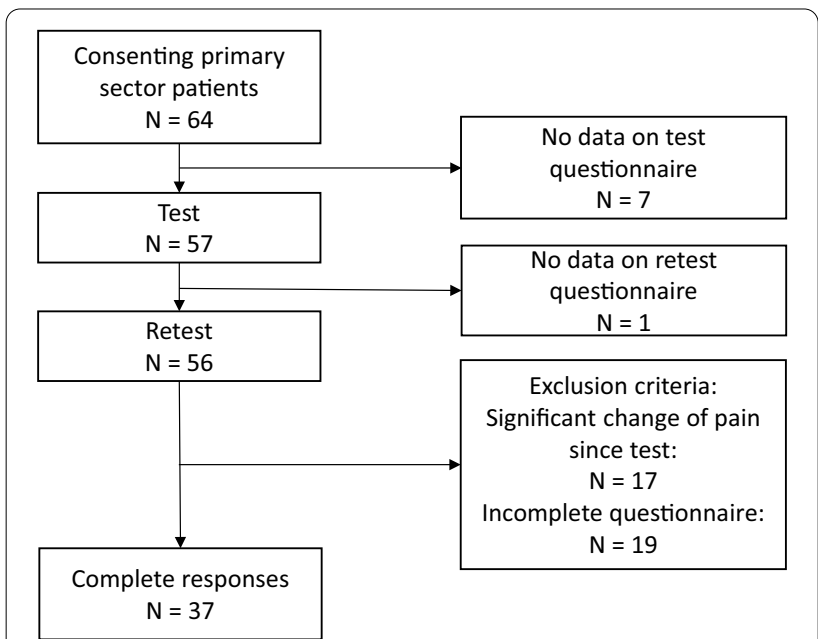

Fig. 2 The test-retest cohort used for reliability analyses of the Patient Enablement Instrument for Back Pain

retest was 37/64 (58\%) and the change of the PEI-BP sum score from test to retest was 3.1 (from 39.6 to 42.7 ). Further baseline characteristics are available in Table 2.

Reasons for non-completion were unknown in both cohorts. Comparison of baseline characteristics revealed no significant statistical differences between the testretest cohort and the GLA:D ${ }^{\circledR}$ Back cohort when tested for age, sex, PEI-BP sum score and ODI sum score.

\section{The content validity cohort}

Five clinics were contacted and three clinics recruited eight, five and three participants, respectively. Two interviews were not transcribed as saturation had been met. Baseline characteristics for the participants included in the analysis are available in Table 2.

\section{Item analyses \\ GLA:D $D^{\circledR}$ back cohort}

The distribution of baseline PEI-BP scores for the GLA: $\mathrm{D}^{\circledR}$ Back cohort are presented in Table 3. Generally, the entire score range was used, however the scores were skewed toward the high scores. Item 6 (Manage your life independently) was skewed the most toward the high scores followed by item 1 (Handle your everyday life). The items with the most even distribution were item 4 (Keep your back in good health) and item 5 (Feel confident with your health).

Overall, there were few missing items with item 4 (keep your back in good health) having the highest amount of missing answers $(2.2 \%)$ and item 1 (handle your everyday life) the lowest amount $(0.4 \%)$ of missing responses (Table 3).

\section{Content validity}

\section{Content validity cohort}

After fourteen semi-structured interviews, the majority of participants chose the same pre-defined response theme. Item 3 (manage your back problem) showed the largest dispersion while item 1 (handle your everyday life) and item 6 (manage your life independently) showed the smallest among the selected response categories.

The participants expressed uncertainty of the comprehension of item 3 and 5 participants found it difficult to distinguish item 3 from one of the other items (item 1, 2 and 4, respectively). Eleven of the participants generally found the questionnaire relevant, whereas the remaining three participants felt they had their back pain under control and considered the questionnaire as irrelevant. Relevance was mostly perceived in two ways, either as relevant in research settings or as relevant at an individual level. Overall, none of the items were deemed as unnecessary. The participants found the instrument adequately representing enablement and considered the scale range as appropriate.

\section{Construct validity \\ Structural validity}

The test for sampling adequacy showed that the sample was factorable (Bartlett's test: $P<0.001 ; \mathrm{KMO}=0.84$ ). The EFA revealed that the PEI-BP had a clear 1-factor structure (eigenvalue $>1$ ) (Fig. 3), and this was the only model analysed. The 1-factor model showed acceptable factor loadings ranging from 0.67 to 0.83 (Table 4). Item 2 and item $6<50 \%$ variance explained by the identified factor whereas the remaining 4 items showed communalities ranging between 0.52 and 0.70 (Table 4).

\section{Hypothesis testing}

The proportion of correctly predicted hypotheses was $88 \%(7 / 8)$ which indicates that the PEI-BP seem to test the intended construct (Table 5).

There was a high correlation between higher patient enablement (PEI-BP) and lower disability (ODI) $(\rho=-0.54)$ and a lower degree of back pain beliefs (BIPQ) $(\rho=-0.58)$. Additionally, the questions about 'understanding your back problem' from the BIPQ and the PEI-BP instruments were highly correlated $(\rho=0.60)$. A moderate correlation was seen between enablement and degree of control and not a high correlation as expected $(\rho=0.43)$. The expected moderate correlations were correctly predicted and indicated that a higher score regarding enablement to some extent correlates with better mental health $(\rho=0.50)$ and a less fear avoidant patient $(\rho=-0.30)$. In contrast, the degree of enablement seems independent of the patients' educational level $(\rho=0.13)$ and of the number of previous episodes of 


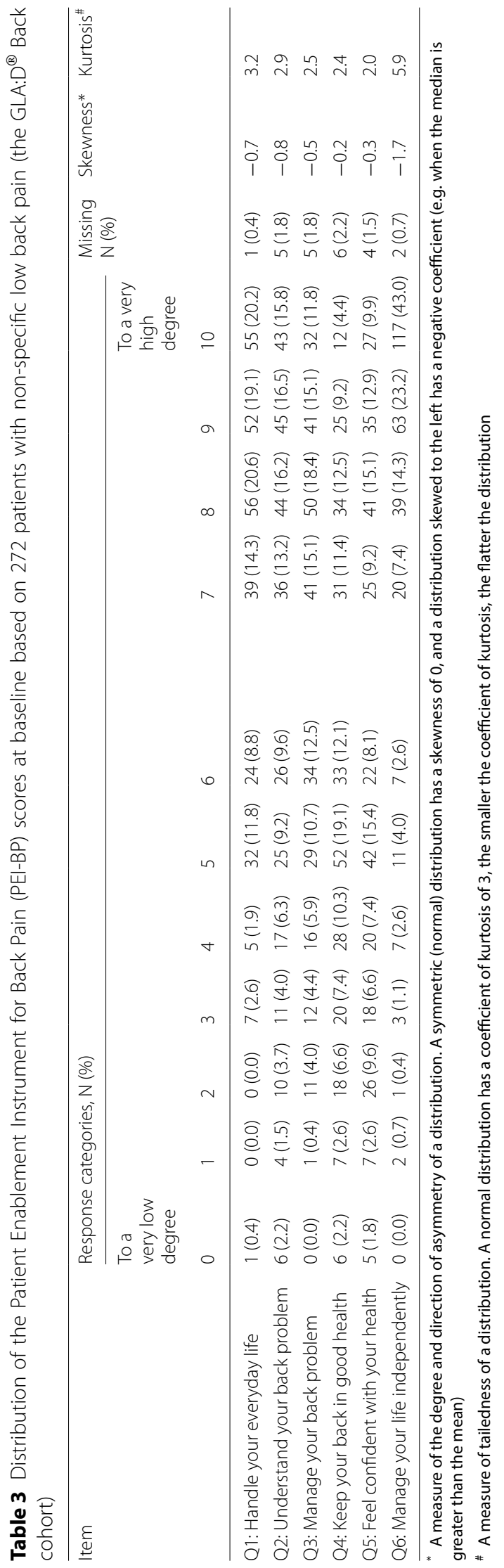




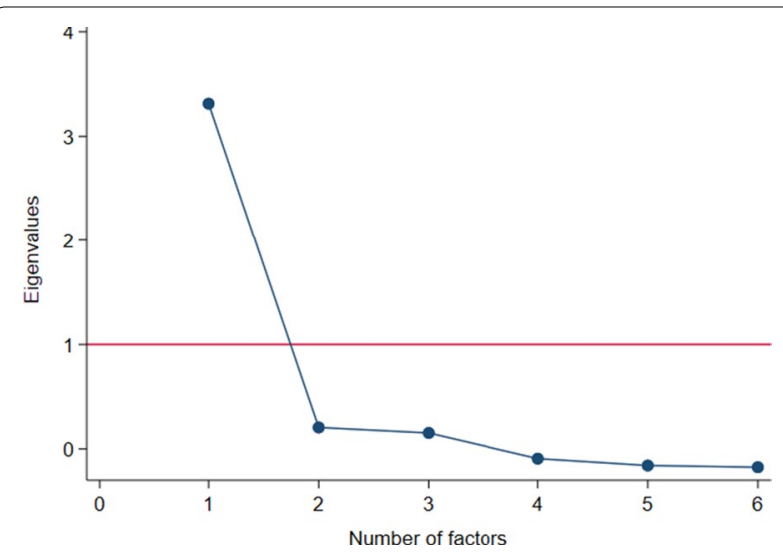

Fig. 3 Scree plot of the Patient Enablement Instrument for Back Pain based on baseline scores from 261 patients with non-specific low back pain (The GLA:D ${ }^{\circledR}$ Back cohort)

Table 4 Factor structure of the Patient Enablement Instrument for Back Pain (PEI-BP) based on 261 patients with non-specific low back pain

\begin{tabular}{lll}
\hline Item & Factor 1 & Communalities \\
\hline Q1: Handle your everyday life & 0.76 & 0.59 \\
Q2: Understand your back problem & 0.70 & 0.48 \\
Q3: Manage your back problem & 0.83 & 0.70 \\
Q4: Keep your back in good health & 0.73 & 0.52 \\
Q5: Feel confident with your health & 0.76 & 0.56 \\
Q6: Manage your life independently & 0.67 & 0.46 \\
\hline
\end{tabular}

LBP $(\rho=-0.04)$ as these hypotheses about low correlations were correctly predicted.

\section{Reliability \\ Internal consistency}

Cronbach's alpha for PEI-BP was 0.88. The alphas of the individual items ranged from 0.85 to 0.87 indicating no reason to perform item reduction.

\section{Test-retest reliability}

The mean response time between the test and retest was 4.9 days $(\mathrm{SD}= \pm 1.1)$. ICC was 0.74 (95\% CI 0.54, 0.86) among the patients.

\section{Measurement error}

The average difference in scores between test and retest was -2.9, which means that participants systematically rated a 2.9 lower score at retest (Fig. 4). The limits of agreement were -12.9 and 7.2 on a scale ranging from 0 to 60 points $(\mathrm{SDC}=10.1)$.

The data were spread uniformly in the Bland and Altman plot (Fig. 4) after deleting two outliers (observations) from the analysis of limits of agreement as their difference of test and retest scores were more than double of the standard deviation.

Table 5 Hypothesis testing in construct validity and construct responsiveness of the Patient Enablement Instrument of Back Pain

\begin{tabular}{|c|c|c|c|c|c|c|c|}
\hline & & \multicolumn{3}{|c|}{ Construct validity } & \multicolumn{3}{|c|}{ Construct responsiveness } \\
\hline & & \multirow[b]{2}{*}{ Hypothesis* } & \multicolumn{2}{|l|}{ Correlations $^{\#}$} & \multirow[b]{2}{*}{ Hypothesis } & \multicolumn{2}{|l|}{ Correlations } \\
\hline & & & Expected & Observed & & Expected & Observed \\
\hline $\mathrm{ODI}_{\text {sum. score }}$ & PEI-BP sum. score & $\mathrm{a}$ & $<-0.5$ & -0.5407 & a & $<-0.5$ & -0.5552 \\
\hline $\mathrm{BIPQ}_{\text {sum. score }}$ & PEI-BP sum. score & a & $<-0.5$ & -0.5808 & a & $<-0.5$ & -0.5375 \\
\hline $\mathrm{BIPQ}_{\mathrm{q} .3}$ & PEI-BP sum. score & $b$ & $>0.5$ & 0.4341 & $b$ & $>0.5$ & 0.5484 \\
\hline $\mathrm{BIPQ}_{\mathrm{q} .7}$ & PEI-BP ${ }_{\mathrm{q} \cdot 2}$ & $b$ & $>0.5$ & 0.5962 & $b$ & $>0.5$ & 0.4635 \\
\hline$F A B Q_{\text {phys. activity }}$ & PEI-BP sum. score & c & -0.3 to -0.5 & -0.3043 & c & -0.3 to -0.5 & -0.4301 \\
\hline SF-36 Mental health & PEI-BP sum. score & d & 0.3 to 0.5 & 0.4986 & $d$ & 0.3 to 0.5 & 0.4069 \\
\hline Educational level & PEI-BP sum. score & e & $\leq 0.3$ & 0.1259 & & & \\
\hline $\begin{array}{c}\text { Number of previous } \\
\text { episodes of LBP }\end{array}$ & PEI-BP sum. score & f & $\geq-0.3$ & -0.0365 & & & \\
\hline
\end{tabular}

$\mathrm{ODI}=$ Oswestry Disability Index; sum. score = summary score; PEI-BP = Patient Enablement Instrument for Back Pain; BIPQ = Brief IIIness Perception Questionnaire; $\mathrm{q}=$ question; $\mathrm{FABQ}_{\text {phys.activity }}=$ Fear Avoidance Belief Questionnaire, the physical activity sub scale; $\mathrm{SF}-36=$ Short Form 36

* Hypothesis: (a) Scales are expected to measure the same construct. The correlation is expected to be negative and high (<-0.5). (b) Scales are expected to measure the same construct. The correlation is expected to be positive and high ( $>0.5)$. (c) Scales are related but do not measure the same construct. The correlation is expected to be negative and moderate $(-0.3$ to -0.5$)$. (d) Scales are related but do not measure the same construct. The correlation is expected to be positive and moderate $(0.3$ to 0.5$)$. (e) Scales are expected not to measure the same construct. The correlation is expected to be positive and low ( $\leq 0.3$ ). (f) Scales are expected not to measure the same construct. The correlation is expected to be negative and low $(\geq-0.3)$

Bold numbers are positive hypotheses and plain numbers are negative hypotheses

\# Spearman's rank correlation coefficient 
Patient Enablement Instrument for Back Pain (0-60)

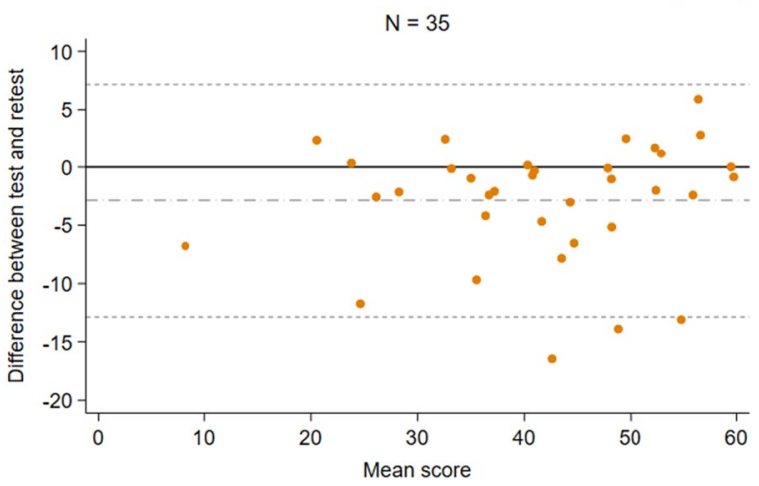

Fig. 4 Bland and Altman plot showing the difference between the test and retest responses on the Patient Enablement Instrument for Back Pain, $\mathrm{N}=35$

\section{Responsiveness}

\section{Construct responsiveness}

The proportion of correctly predicted hypotheses was $83 \%(5 / 6)$ (Table 5).

The results indicated that a change to a higher degree of enablement highly correlates with a change to a lower degree of disability $(\rho=-0.56)$, lower degree of illness beliefs $(\rho=-0.54)$ and a higher degree of feeling of control $(\rho=0.55)$. When comparing the change score for the items about 'understanding your back pain/ back problem' from the BIPQ and the PEI-BP instruments it showed a moderate positive correlation $(\rho=0.46)$, and not high correlation as expected. The expected moderate correlations were correctly predicted and indicated that a change to a higher degree of enablement to some extent correlates with a change to better mental health $(\rho=0.41)$ and a change to a less fear avoidant patient $(\rho=-0.43)$ after an intervention. An overview of the change scores from baseline to 4 months is shown in Fig. 5 (PEI-BP sum score) and in Fig. A1 of Additional file 2 (for each item of the PEI-BP).

\section{Floor and ceiling effects}

A floor and ceiling effect of $0 \%$ and $29.9 \%$, respectively, were found using the scale width method (Table 6). Especially item 6 (manage your life independently) contributed to the ceiling effect as $43 \%$ of the baseline scores had a maximum score of 10 (Fig. $5+$ Table 3 ).
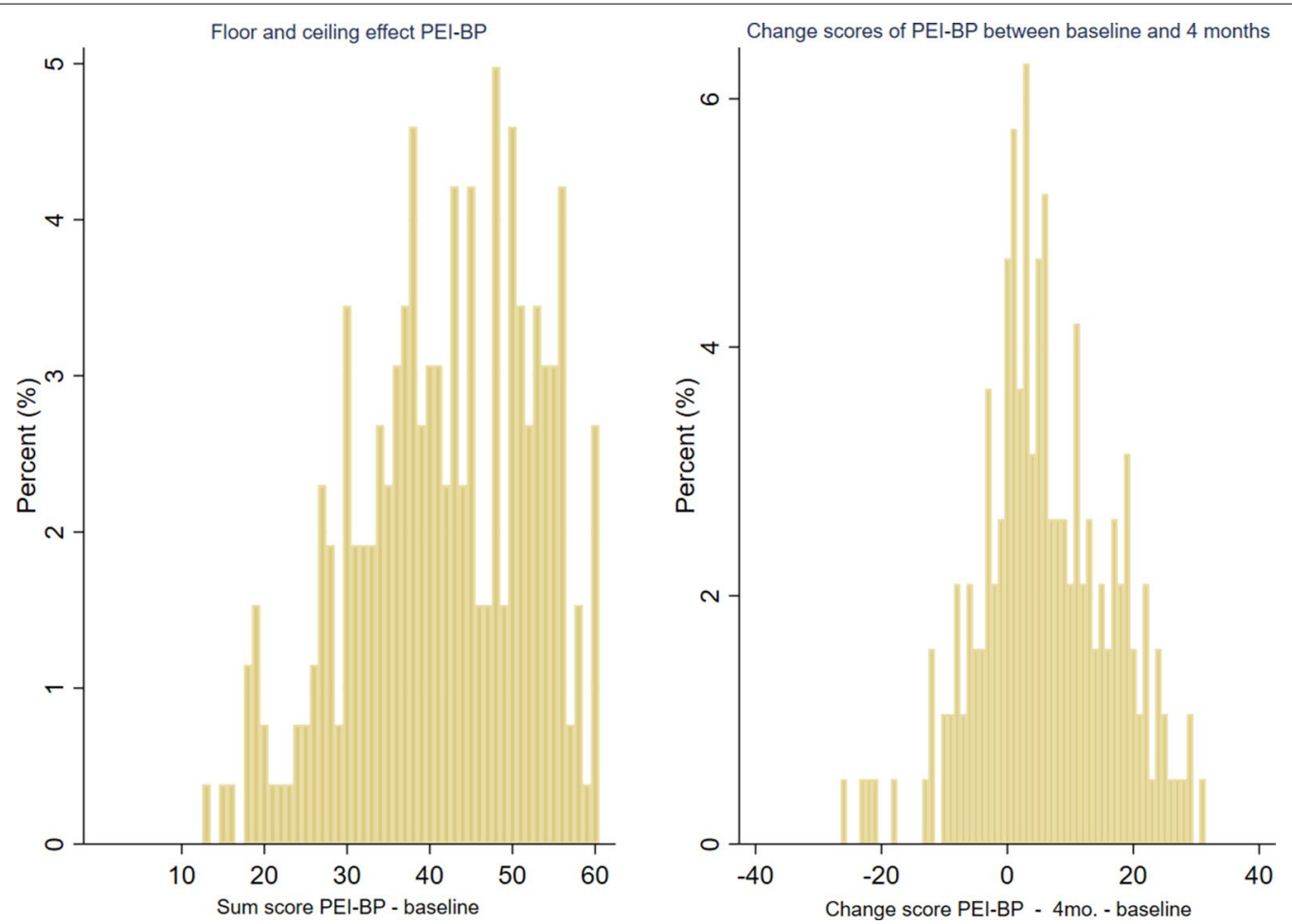

Fig. 5 The distribution of baseline sum scores and change scores between baseline and 4 mo. follow-up on the Patient Enablement Instrument for Back Pain (PEI-BP) based on 261 and 191 participants, respectively, with non-specific low back pain. A higher score indicates higher enablement 
Table 6 Floor and ceiling effects of the Patient Enablement Instrument for Back pain based on 261 participants with nonspecific low back pain

\begin{tabular}{|c|c|c|c|c|c|}
\hline & \multirow{2}{*}{$\begin{array}{l}\text { Scale } \\
\text { range }\end{array}$} & \multicolumn{2}{|c|}{ Classical method } & \multicolumn{2}{|c|}{ Scale width method } \\
\hline & & $\begin{array}{l}\text { Floor } \\
\text { effect (\%) }\end{array}$ & $\begin{array}{l}\text { Ceiling } \\
\text { effect (\%) }\end{array}$ & $\begin{array}{l}\text { Floor } \\
\text { effect (\%) }\end{array}$ & $\begin{array}{l}\text { Ceiling } \\
\text { effect } \\
(\%)\end{array}$ \\
\hline $\begin{array}{l}\text { PEl-BP } \\
\text { sum } \\
\text { score }\end{array}$ & $0-60$ & 0.0 & 2.7 & 0 & 29.9 \\
\hline
\end{tabular}

\section{Discussion}

We have described the development and measurement properties of the PEI-BP that focusses on the enablement of people to manage their back pain. Overall, the results showed satisfactory construct validity (structural validity and hypothesis testing) and reliability (internal consistency, test-retest reliability and measurement error) of the PEI-BP for use in research. The PEI-BP seemed responsive with higher PEI-BP scores relating to less disability and a less threatening view of back pain and to overall positive changes in health between baseline and follow-up. The skewed distribution towards the high scores indicates a problematic ceiling effect as the intention is to use PEI-BP to measure change over time. As the scale range on the original PEI was $0-2$ compared to our $0-10$, this issue has to our knowledge not been identified previously for individual items.

\section{Content validity}

The questionnaire showed acceptable content validity as the participants in the content validity cohort generally found the questionnaire meaningful. However, they did find that item 3 overlapped with other items and therefore caused some uncertainty regarding its comprehensibility. A rewording of item 3 or addition of clarifications to each of the items, might be a way of improving the content validity of the PEI-BP, however based on the quantitative analysis, the overlap between item 3 and other items were not apparent. For example, we did not find an increased number of missing responses for item 3, nor did we find less impact on other clinimetric properties and therefore a rewording of item 3 is not of high priority.

\section{Construct validity}

Exploratory factor analysis demonstrated a 1-factor model suggesting that the instrument is unidimensional and indeed measures the construct of patient enablement. This result is supported by the majority (3/4) of previous studies using factor analysis on the original PEI which have also shown unidimensionality $[10,11$, 13, 16].

The PEI-BP also seem to be valid in terms of measuring what it purports to measure when compared to instruments measuring back-related disability (ODI) and back pain beliefs (BIPQ). The PEI-BP seems related to the feeling of control, but not as highly as expected. This indicates a difference from the construct measured by BIPQ-control ("how much control do you feel you have over your back pain") and maybe because PEI-BP covers a broader aspect than control as purely control of symptoms. As expected, PEI-BP seems moderately related to physical activity (FABQ) and Mental health (SF-36) and therefore, they are related but not measuring the same construct. Generally, these results are comparable to previous studies which have used the original PEI-BP such as Enthoven et al. who found a fair to moderate relationship with less disability and better mental and general health for a cohort of patients with chronic musculoskeletal pain [13]. Likewise, Haughney et al. found an association between the PEI and improved quality of life for patients with asthma using a modified version of the PEI [14]. However, a randomised controlled trial on people with chronic back pain by Eardley et al. did not show an association between enablement and disability at 5 weeks, potentially indicating a less robust relationship between the PEI and disability (Roland Morris Disability Questionnaire) [49]. Lastly with regards to the included hypotheses, we did not find that enablement was related to patients' educational level or the number of previous episodes of LBP. In contrast, Ozvacić Adzić et al. found that the enablement score increased with higher educational level [15].

\section{Reliability}

The internal consistency of the PEI-BP was satisfactory $(\alpha=0.88)$ [24]. All the items seem to be interrelated and to measure the same construct. The result is comparable to studies on the original PEI within primary care with Cronbach's alpha values between 0.84 and 0.93 [7, 10, 12]. The SDC at 10.1 points illustrates that a patient would have to change more than $1 / 6$ of the scale range for it to be a true change.

\section{Responsiveness}

The PEI-BP was responsive when compared to commonly used instruments for patients with LBP (disability (ODI) $[r=-0.56]$ and back pain beliefs (BIPQ) $[r=-0.54])$. One hypothesis comparing 'understanding your back 
pain / back problem' (Table 5) did reach the pre-defined level of correlation ( $r=46$ versus $r>0.5)$, nevertheless, we believe that the PEI-BP can be used longitudinally to measure change over time and as an outcome measure.

\section{Floor and ceiling effects}

The results of our hypothesis testing showed a high correlation between a low disability (ODI) score and a high enablement (PEI-BP) score, and as the average baseline ODI score was quite low in our population, this might explain part of the high PEI-BP score at baseline. The potential ceiling effect should be addressed in further development of the PEI-BP. From the item analysis, item 6 (manage your life independently) and item 1 (handle your everyday life) particularly seem to add to this effect. The original PEI was not developed to measure change over time and the scale range was smaller, however, Remelhe et al. did also identify a tendency for ceiling effects when using the original scale (0-2) [11]. Because our population scores high on especially the ability to manage and handle life already at the first response, one way of addressing the ceiling effect could be to make the anchors more extreme, i.e. changing from 'to a very high degree' to 'an extreme degree' or 'completely'. Potentially, removing item 6 in populations with minor activity limitations, might have a positive impact on the identified ceiling effect. Importantly, floor- and ceiling effects are sensitive to the population being studied, so this might not be a problem if the instrument is used in other more severely affected LBP patients.

\section{Strengths and weaknesses}

The relatively large number of participants is a strength in the context of the planned statistical analysis, although the number of included participants in the test-retest cohort preferable should have been higher and therefore, the results based on those data should be interpreted with caution.

The use of 2 cohorts for different analysis is also a potential weakness, however the analyses revealed no statistical baseline differences between the two cohorts.

The majority of participants were females, which might reduce the generalisability of the study $[8,50-52]$, however, other studies have not found a significant difference in score with regards to sex $[16,53]$. Additionally, the mentioned studies were based on PEI and not PEI-BP and therefore, interpretation and comparison should be made with caution.

\section{Conclusions}

Based on the Patient Enablement Instrument, we developed the Patient Enablement Instrument for Back Pain, PEI-BP. The PEI-BP has acceptable content validity, construct validity, reliability (internal consistency, test-retest reliability and measurement error) and responsiveness. Thus, the PEI-BP can be considered a valid and reliable tool to measure enablement in people seeking care for non-specific LBP in research settings. Further testing of the PEI-BP in populations with more severe LBP is recommended.

\section{Abbreviations}

BIPQ: Brief illness perception questionnaire; Cl: Confidence intervals; COSMIN: COnsensus-based Standards for the selection of health Measurement INstruments; EFA: Explorative factor analysis; FABQ: Fear-avoidance beliefs questionnaire; GLA:D ${ }^{\circledR}$ : Good life with osteoarthritis in Denmark; LBP: Low back pain; ODI: Oswestry disability index; OPEN: Open Patient data Explorative Network; PEl: Patient enablement instrument; PEI-BP: Patient enablement instrument for back pain; SBT: STarT back tool; SDC: Smallest detectable change; SF-36: Short form 36 .

\section{Supplementary Information}

The online version contains supplementary material available at https://doi. org/10.1186/s12955-021-01758-0.

Additional file 1: A Danish, English and Swedish version of the Patient Enablement Instrument for Back Pain questionnaire (PEI-BP).

Additional file 2: A figure showing the change scores from baseline to 4 months of the six individual items of the Patient Enablement Instrument for Back Pain.

\section{Acknowledgements}

The authors would like to thank Marianne Horn and Adrian Daniel House for the back translation of the PEI-BP questionnaire and also Karin Ilsøe Nielsen and Mia Månsson for the content validity study. Additionally, the authors would like to thank Tenna Bolby and Maria Ebsen Sørensen for data collection for the test-retest study.

\section{Authors' contributions}

AMN: Funding acquisition, project administration, methodology, formal analysis, data curation, writing original draft. JH: Funding acquisition, conceptualization, methodology, writing: review and editing, supervision. AK: Funding acquisition, conceptualization, investigation, data curation, writing: review and editing, supervision. BÖ: Conceptualization, methodology, writing: review and editing. PE: Conceptualization, methodology, formal analysis, writing: review and editing. AA: Methodology, formal analysis, writing: review and editing. HHL: Funding acquisition, methodology, formal analysis, supervision, writing: review and editing. All authors are to give input and approve the final manuscript.

\section{Funding}

AMN was partially financially funded by the Danish Foundation for Chiropractic Research and Post Graduate Education, Denmark. AKs position at SDU is partly funded by the Danish Foundation for Chiropractic Research and Post Graduate Education. The funding bodies had no control over design, conduct, data, analysis, review, reporting, or interpretation of the research conducted.

\section{Availability of data and materials}

The datasets used and analysed during the current study are available from the corresponding author on reasonable request. 


\section{Declarations}

\section{Ethics approval and consent to participate}

The included patients were informed about the study and written consent was obtained. The data collection had obtained authorisation from the Danish Data Protection Agency (DPA) as part of the University of Southern Denmark's institutional authorisation (GLA:D ${ }^{\circledR}$ Back cohort: DPA no. 2015-57-0008 SDU no. 17/30591, Test-retest cohort: SDU no. 10037). As treatment was not affected by participation in the study, under Danish law, this study did not need ethical approval (Act on Research Ethics Review of Health Research Projects, October 2013, Sect. 14.2) [54]. The conduct of the study complied with the Declaration of Helsinki.

\section{Consent for publication}

Not applicable.

\section{Competing interests}

The authors have no financial or non-financial competing interests to declare.

\section{Author details}

${ }^{1}$ Department of Sports Science and Clinical Biomechanics, University of Southern Denmark, Campusvej 55, 5230 Odense M, Denmark. ${ }^{2}$ Chiroprac tic Knowledge Hub, Campusvej 55, 5230 Odense M, Denmark. ${ }^{3}$ Department of Health, Medicine and Caring Sciences, Division of Prevention, Rehabilitation and Community Medicine, Unit of Physiotherapy, Linköping University, Linköping, Sweden.

Received: 23 November 2020 Accepted: 29 March 2021

Published online: 09 April 2021

\section{References}

1. Disease GBD, Injury I, Prevalence C. Global, regional, and national incidence, prevalence, and years lived with disability for 310 diseases and injuries, 1990-2015: a systematic analysis for the Global Burden of Disease Study 2015. Lancet. 2016;388(10053):1545-602.

2. Hartvigsen J, Hancock MJ, Kongsted A, Louw Q, Ferreira ML, Genevay S, et al. What low back pain is and why we need to pay attention. Lancet. 2018;391(10137):2356-67.

3. Foster NE, Anema JR, Cherkin D, Chou R, Cohen SP, Gross DP, et al. Prevention and treatment of low back pain: evidence, challenges, and promising directions. Lancet. 2018;391(10137):2368-83.

4. Chiarotto A, Deyo RA, Terwee CB, Boers M, Buchbinder R, Corbin TP, et al. Core outcome domains for clinical trials in non-specific low back pain. Eur Spine J. 2015:24(6):1127-42.

5. Howie JG, Heaney D, Maxwell M. Quality, core values and the general practice consultation: issues of definition, measurement and delivery. Fam Pract. 2004;21(4):458-68.

6. Howie JG, Heaney DJ, Maxwell M: Measuring quality in general practice. Pilot study of a needs, process and outcome measure. Occasional paper (Royal College of General Practitioners) 1997(75):i.

7. Howie JG, Heaney DJ, Maxwell M, Walker JJ. A comparison of a Patient Enablement Instrument (PEI) against two established satisfaction scales as an outcome measure of primary care consultations. Fam Pract. 1998;15(2):165-71.

8. Howie JG, Heaney DJ, Maxwell M, Walker JJ, Freeman GK, Rai H. Quality at general practice consultations: cross sectional survey. BMJ. 1999:319(7212):738-43.

9. Hudon C, Fortin M, Rossignol F, Bernier S, Poitras ME. The Patient Enablement Instrument-French version in a family practice setting: a reliability study. BMC Fam Pract. 2011;12:71.

10. Lam CLK, Yuen NYK, Mercer SW, Wong W. A pilot study on the validity and reliability of the Patient Enablement Instrument (PEI) in a Chinese population. Fam Pract. 2010;27(4):395-403

11. Remelhe M, Teixeira PM, Lopes I, Silva L. Correia de Sousa J: The modified patient enablement instrument: a Portuguese cross-cultural adaptation, validity and reliability study. NPJ Prim Care Respir Med. 2017;27:16087
12. Roost M, Zielinski A, Petersson C, Strandberg EL. Reliability and applicability of the Patient Enablement Instrument (PEI) in a Swedish general practice setting. BMC Fam Pract. 2015:16:31.

13. Enthoven P, Peolsson A, Ludvigsson ML, Wibault J, Peterson G, Oberg B. Validity, internal consistency and self-rated change of the patient enablement instrument in patients with chronic musculoskeletal pain. J Rehabil Med. 2019;51(8):587-97.

14. Haughney J, Cotton P, Rosen JP, Rosen JP, Morrison K, Price D. The use of a modification of the Patient Enablement Instrument in asthma. Prim Care Respir J. 2007;16(2):89-92.

15. Ozvacić Adzić Z, Katić M, Kern J, Lazić D, Cerovecki Nekić V, Soldo D. Patient, physician, and practice characteristics related to patient enablement in general practice in Croatia: cross-sectional survey study. Croat Med J. 2008:49(6):813-23.

16. Kurosawa S, Matsushima M, Fujinuma Y, Hayashi D, Noro I, Kanaya T, et al. Two principal components, coping and independence, comprise patient enablement in Japan: cross sectional study in Tohoku area. Tohoku J Exp Med. 2012;227(2):97-104.

17. Tolvanen E, Koskela TH, Helminen M, Kosunen E. The validity and reliability of the patient enablement instrument (PEI) after GP appointments in Finnish health care centres. J Patient Rep Outcomes. 2020;4(1):79.

18. Mokkink LB, Terwee CB, Patrick DL, Alonso J, Stratford PW, Knol DL, et al. The COSMIN study reached international consensus on taxonomy, terminology, and definitions of measurement properties for health-related patient-reported outcomes. J Clin Epidemiol. 2010;63(7):737-45.

19. Kottner J, Audige L, Brorson S, Donner A, Gajewski BJ, Hrobjartsson A et al. Guidelines for Reporting Reliability and Agreement Studies (GRRAS) were proposed. J Clin Epidemiol. 2011:64(1):96-106.

20. Kongsted A, Hartvigsen J, Boyle E, Ris I, Kjaer P, Thomassen L, et al. $G L A: D(R)$ Back: group-based patient education integrated with exercises to support self-management of persistent back pain - feasibility of implementing standardised care by a course for clinicians. Pilot Feasibility Stud. 2019;5:65.

21. Kjaer P, Kongsted A, Ris I, Abbott A, Rasmussen CDN, Roos EM, et al. $G L A: D((R))$ Back group-based patient education integrated with exercises to support self-management of back pain - development, theories and scientific evidence. BMC Musculoskelet Disord. 2018;19(1):418.

22. Kongsted A, Ris I, Kjaer P, Vach W, Morsø L, Hartvigsen J. GLA:D ${ }^{\circledR}$ Back: implementation of group-based patient education integrated with exercises to support self-management of back pain - protocol for a hybrid effectiveness-implementation study. BMC Musculoskelet Disord. 2019;20(1):85

23. Vet HCWd, Adèr HJ, Terwee CB, Pouwer F: Are factor analytical techniques used appropriately in the validation of health status questionnaires? A systematic review on the quality of factor analysis of the SF-36. Quality of Life Research 2005, 14(5):1203-1218.

24. Vet HCWd: Measurement in medicine: a practical guide. Cambridge: Cambridge University Press; 2011.

25. Strong J, Ashton R, Chant D. Pain intensity measurement in chronic low back pain. Clin J Pain. 1991;7(3):209-18.

26. Hill JC, Dunn KM, Lewis M, Mullis R, Main CJ, Foster NE, et al. A primary care back pain screening tool: identifying patient subgroups for initial treatment. Arthritis Rheum. 2008;59(5):632-41.

27. Morso L, Albert H, Kent P, Manniche C, Hill J. Translation and discriminative validation of the STarT Back Screening Tool into Danish. Eur Spine J. 2011;20(12):2166-73.

28. Fairbank JC, Pynsent PB: The Oswestry Disability Index. Spine (Phila Pa 1976) 2000, 25(22):2940-2952; discussion 2952

29. Lauridsen HH, Hartvigsen J, Manniche C, Korsholm L, Grunnet-Nilsson N. Danish version of the Oswestry Disability Index for patients with low back pain. Part 1: Cross-cultural adaptation, reliability and validity in two different populations. Eur Spine J 2006, 15(11):1705-1716.

30. Lauridsen $\mathrm{HH}$, Hartvigsen J, Manniche C, Korsholm L, Grunnet-Nilsson N. Danish version of the Oswestry disability index for patients with low back pain. Part 2: Sensitivity, specificity and clinically significant improvement in two low back pain populations. Eur Spine J 2006, 15(11):1717-1728.

31. Leysen M, Nijs J, Meeus M, Paul van Wilgen C, Struyf F, Vermandel A et al. Clinimetric properties of illness perception questionnaire revised $(I P Q-R)$ and brief illness perception questionnaire (Brief IPQ) in patients 
with musculoskeletal disorders: A systematic review. Man Ther 2015, 20(1):10-17.

32. Broadbent E, Wilkes C, Koschwanez H, Weinman J, Norton S, Petrie KJ. A systematic review and meta-analysis of the Brief IIIness Perception Questionnaire. Psychol Health. 2015;30(11):1361-85.

33. Waddell G, Newton M, Henderson I, Somerville D, Main CJ. A Fear-Avoidance Beliefs Questionnaire (FABQ) and the role of fear-avoidance beliefs in chronic low back pain and disability. Pain. 1993;52(2):157-68.

34. Grotle M, Brox Jl, Vollestad NK. Reliability, validity and responsiveness of the fear-avoidance beliefs questionnaire: methodological aspects of the Norwegian version. J Rehabil Med. 2006;38(6):346-53.

35. McHorney CA, Ware JE, Jr., Lu JF, Sherbourne CD. The MOS 36-item ShortForm Health Survey (SF-36): III. Tests of data quality, scaling assumptions, and reliability across diverse patient groups. Med Care 1994, 32(1):40-66.

36. Bjorner JB, Thunedborg K, Kristensen TS, Modvig J, Bech P. The Danish SF-36 Health Survey: translation and preliminary validity studies. J Clin Epidemiol. 1998;51(11):991-9.

37. OPEN: Odense Patient data Explorative Network [https://www.sdu.dk/en/ om_sdu/institutter_centre/klinisk_institut/forskning/forskningsenheder/ open.aspx] 2020 July 30

38. SurveyXact: SurveyXact [https://www.surveyxact.com/] 2020 August 31

39. Hair JF, Jr., Black WC, Babin BJ, Anderson RE. Multivariate data analysis, Seventh, Pearson new international edn. Harlow: Pearson Education Limited; 2014

40. Floyd FJ, Widaman KF. Factor analysis in the development and refinement of clinical assessment instruments. Psychol Assess. 1995;7(3):286-99.

41. Cohen J: Statistical Power Analysis for the Behavioral Sciences, 2nd;2; edn. Florence: Routledge Ltd; 1988.

42. Terwee CB, Mokkink LB, Knol DL, Raymond WJGO, Bouter LM. Henrica CWdV: Rating the methodological quality in systematic reviews of studies on measurement properties: a scoring system for the COSMIN checklist. Qual Life Res. 2012;21(4):651-7.

43. Qin S, Nelson L, McLeod L, Eremenco S, Coons SJ. Assessing test-retest reliability of patient-reported outcome measures using intraclass correlation coefficients: recommendations for selecting and documenting the analytical formula. Qual Life Res. 2018;28(4):1029-33.

44. Bland JM, Altman DG. Statistical methods for assessing agreement between two methods of clinical measurement. Lancet (London, England). 1986; 1 (8476):307.
45. de Vet HCW, Terwee CB, Knol DL, Bouter LM. When to use agreement versus reliability measures. J Clin Epidemiol. 2006;59(10):1033-9.

46. Terwee CB, Bot SD, de Boer MR, van der Windt DA, Knol DL, Dekker J, et al. Quality criteria were proposed for measurement properties of health status questionnaires. J Clin Epidemiol. 2007;60(1):34-42.

47. McHorney CA, Tarlov AR. Individual-patient monitoring in clinical practice: are available health status surveys adequate? Qual Life Res. 1995;4(4):293-307.

48. Davidson M, Keating JL. A comparison of five low back disability questionnaires: reliability and responsiveness. Phys Ther. 2002;82(1):8-24.

49. Eardley S, Brien S, Little P, Prescott P, Lewith G. Professional kinesiology practice for chronic low back pain: single-blind, randomised controlled pilot study. Complementary Med Res. 2013;20(3):180-8.

50. Pawlikowska TR, Walker JJ, Nowak PR, Szumilo-Grzesik W. Patient involvement in assessing consultation quality: a quantitative study of the Patient Enablement Instrument in Poland. Health Expect. 2010;13(1):13-23.

51. Skarbalienè A, Jurgutis A, Strandberg EL, Pawlikowska T. Patient involvement in assessing consultation quality: validation of patient enablement instrument (PEI) in Lithuanian general practice. BMC Fam Pract. 2019:20(1):167-166.

52. MacPherson H, Mercer SW, Scullion T, Thomas KJ. Empathy, enablement, and outcome: an exploratory study on acupuncture patients' perceptions. J Altern Complement Med. 2003;9(6):869-76.

53. Mead N, Bower P, Roland M. Factors associated with enablement in general practice: cross-sectional study using routinely-collected data. $\mathrm{Br} J$ Gen Pract. 2008;58(550):346-52.

54. Danish National Committee on Biomedical Research Ethics: Act on research ethics review of health research projects [https://en.nvk.dk/ rules-and-guidelines/act-on-research-ethics-review-of-health-researchprojects] 20207 April

\section{Publisher's Note}

Springer Nature remains neutral with regard to jurisdictional claims in published maps and institutional affiliations.
Ready to submit your research? Choose BMC and benefit from:

- fast, convenient online submission

- thorough peer review by experienced researchers in your field

- rapid publication on acceptance

- support for research data, including large and complex data types

- gold Open Access which fosters wider collaboration and increased citations

- maximum visibility for your research: over $100 \mathrm{M}$ website views per year

At BMC, research is always in progress.

Learn more biomedcentral.com/submissions 